\title{
Pyrolysis of Coconut Shell: An Experimental Investigation
}

\author{
E. Ganapathy Sundaram*a and E. Natarajan ${ }^{\mathrm{b}}$ \\ ${ }^{*}$ a Department of Mechanical Engineering, Velammal Engineering College, Chennai 600 066, Tamilnadu, India \\ bInstitute for Energy Studies, College of Engineering, Anna University, Guindy, Chennai 600 025, Tamilnadu, India
}

Received 30 August 2008; accepted 20 January 2009

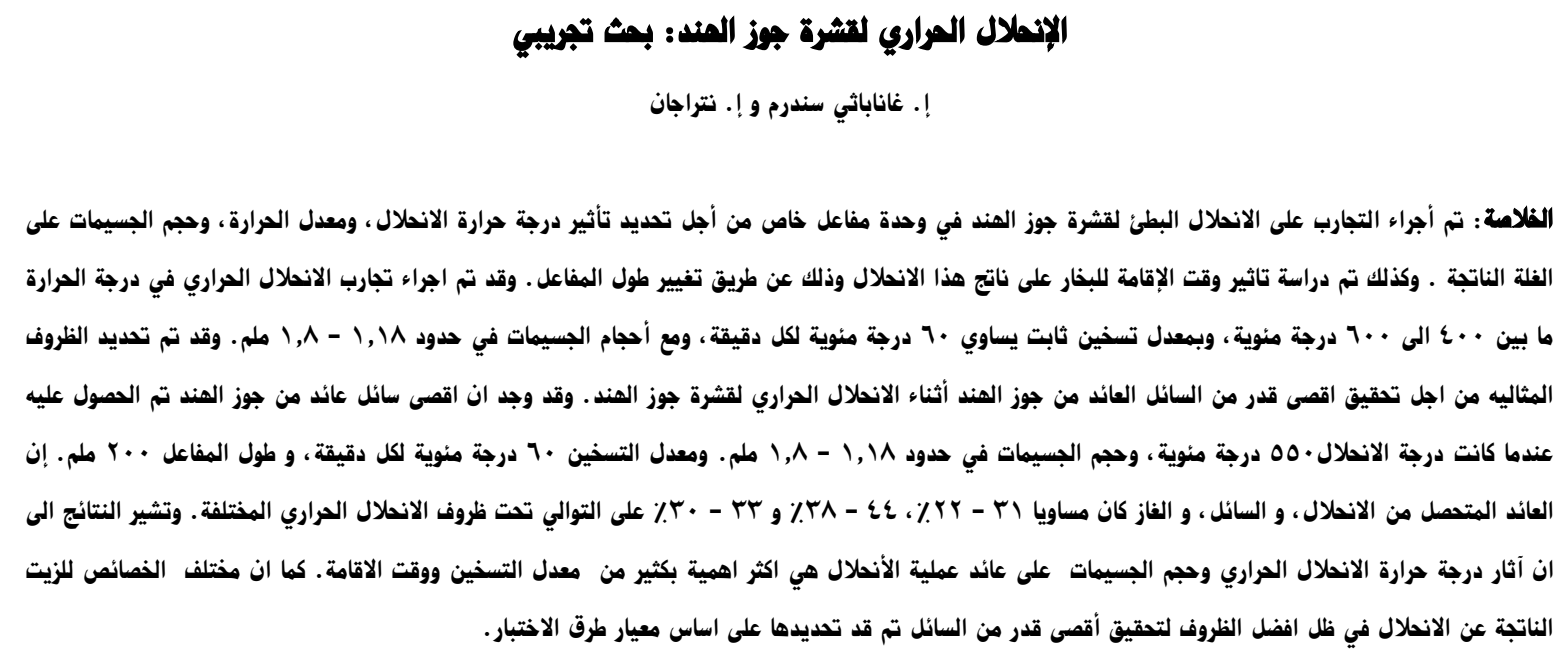

الهزردات الهنتاهية: الانحلال الحراري البطئ، قشرة جوز الهند، اعادة التدوير، الكتلة الحيوية.

\begin{abstract}
Fixed-bed slow pyrolysis experiments of coconut shell have been conducted to determine the effect of pyrolysis temperature, heating rate and particle size on the pyrolysis product yields. The effect of vapour residence time on the pyrolysis yield was also investigated by varying the reactor length. Pyrolysis experiments were performed at pyrolysis temperature between 400 and $600^{\circ} \mathrm{C}$ with a constant heating rate of $60^{\circ} \mathrm{C} / \mathrm{min}$ and particle sizes of 1.18-1.80 mm. The optimum process conditions for maximizing the liquid yield from the coconut shell pyrolysis in a fixed bed reactor were also identified. The highest liquid yield was obtained at a pyrolysis temperature of $550{ }^{\circ} \mathrm{C}$, particle size of $1.18-1.80 \mathrm{~mm}$, with a heating rate of $60{ }^{\circ} \mathrm{C} / \mathrm{min}$ in a $200 \mathrm{~mm}$ length reactor. The yield of obtained char, liquid and gas was $22-31 \mathrm{wt} \%, 38-44 \mathrm{wt} \%$ and $30-33 \mathrm{wt} \%$ respectively at different pyrolysis conditions. The results indicate that the effects of pyrolysis temperature and particle size on the pyrolysis yield are more significant than that of heating rate and residence time. The various characteristics of pyrolysis oil obtained under the optimum conditions for maximum liquid yield were identified on the basis of standard test methods.
\end{abstract}

Keywords: Slow pyrolysis; Coconut shell; Recycling; Biomass

\section{Introduction}

The scarcity of fossil fuels, increasing their costs and increasing the environmental pollution from fossil fuel combustion will make renewable energy sources as more attractive one. Agricultural residue is one form of biomass, which is readily available but is largely not utilized in energy recovery schemes. Pyrolysis is one of thermo chemical process which converts the solid biomass in to liquid (bio-oil), gas and solid. The liquid product, pyrolytic oil, approximates to biomass in elemental composition, and is composed of a very complex mixture of oxygenated hydrocarbons. It is useful as a fuel, may be added to petroleum refinery feed stocks or upgraded by catalysts to

*Corresponding author’s e-mail: ganapathy_sundar@yahoo.com produce premium grade refined fuels, or may have a potential to be used as a chemical feed stocks. Bio-oils are generally preferred products because of their high calorific value, the gross calorific value of the bio oil obtained from pyrolysis of rapeseed oil cake (Suat Ucar and Ahmet, 2008), empty fruit bunches (Abdullah and Gerhauser, 2008) and Cashew nut shell (Das et al. 2004) were 33, 36 and $40 \mathrm{MJ} / \mathrm{kg}$ respectively, their ease of transportation and storage, their low nitrogen and sulphur content and their opportunity to be converted into chemicals. Coconut shell as an agricultural residue is available abundant in India with an annual production of more than 0.94 million tons in the year of 1994 and projected with the production of more than 1.50 million tones for the year of 2010. Coconut shell is more suitable for pyrolysis process, since they contain less amount of ash, more amount of 
volatile matter and available with lower cost in rural areas during all the sessions of the year. Its higher fixed carbon content leads to the usage of solid obtained from the pyrolysis process as an activated carbon material for water treatment purpose. Therefore, a practical method should be applied to pyrolyse coconut shell for providing the valuable product.

Ozlem Onay et al. (2006) pyrolyzed rapeseed in a free fall reactor under nitrogen flow to determine the role of pyrolysis temperature and sweeping gas flow rate on the bio-oil yield at atmospheric pressure. Esin Apaydin-Varol et al. [(2007) investigated the effects of temperature on the product yields and its composition of pistachio shell in a slow pyrolysis with fixed bed reactor. Ozlem Onay (2007) performed fast pyrolysis of safflower seed to identify optimum process conditions for maximizing the biooil yield in a fixed bed reactor, the optimum process conditions were: final pyrolysis temperature $600^{\circ} \mathrm{C}$, sweeping gas flow rate $100 \mathrm{~cm}^{3} / \mathrm{min}$ and heating rate $300{ }^{\circ} \mathrm{C} / \mathrm{min}$. Fixed-bed slow and fast pyrolysis experiments have been conducted on a sample of rapeseed to investigate the effects of heating rate, pyrolysis temperature, particle size and sweep gas velocity on the pyrolysis product yields and its chemical compositions by Ozlem Onay et al. (2004). Sevgi Sensoz et al (2008) pyrolyzed safflower seed press cake in a fixed-bed reactor to determine the effects of pyrolysis temperature, heating rate and sweep gas flow rates on the yields of the products using pyrolysis temperatures between 400 and $600^{\circ} \mathrm{C}$ with a heating rates of 10 , 30 and $50{ }^{\circ} \mathrm{C} / \mathrm{min}$. Ayse E. Putun et al (2002) conducted the slow pyrolysis of soybean cake in a fixed-bed reactor under three different atmospheres: static, for determining the effects of pyrolysis temperature and particle size, nitrogen and steam for determining the product yields. Pyrolysis of corn stalks with batch wise in a laboratory captive sample reactor wire mesh at atmospheric pressure was carried out by Zabaniotou et al (2007) by varying the temperature $\left(470-710{ }^{\circ} \mathrm{C}\right)$ with an average heating rate of $60{ }^{\circ} \mathrm{C} / \mathrm{s}$ and a reaction time of $0.2 \mathrm{~s}$. The effect of the process conditions such as heating rate, temperature and particle size on the product distribution, gas composition and char reactivity of olive waste and straw at high temperature $\left(800-1000^{\circ} \mathrm{C}\right)$ in a free-fall reactor at pilot scale was carried over by Rolando Zanzi et al (2002). Olive bagasse was pyrolyzed in a fixed bed reactor (Sensoz et al. 2006). Alberto J. Tsamba et al (2006) studied the pyrolysis characteristics and global kinetics of coconut and cashew nut shells. For the coconut shell, the grater mass loss was reported at the temperature interval of $280-415^{\circ} \mathrm{C}$ at the heating rate of $10^{\circ} \mathrm{C} / \mathrm{min}$.

The literature study shows, the yield and composition of pyrolysis products greatly depends on the reaction parameters: temperature, particle size of the fuel, heating rate and residence time. Presently, there are limited researches that reported specifically about the effect of temperature, heating rate, particle size and residence time on the product yields of coconut shell pyrolysis. The optimum process conditions to produce highest liquid yield from coconut shell are also not available in the literature.
Yun Ju Hwang et al (2008) extracted high capacity disordered carbons from coconut shells as anode materials for lithium batteries. Afrane et al. (2008) and Gratuito et al. (2008) produced activated carbons from the coconut shells under the physical methods. Dinesh Mohan et al (2008) studied the wastewater treatment by the low cost activated carbons derived from coconut shells and coconut shell fibers. Amudaa et al. (2007) produced a highly effective adsorbent material from the coconut shell combined with aquatic waste for the removal of heavy metal from industrial wastewater. Wei Su et al (2006) prepared micro porous activated carbon from raw coconut shell. Furthermore, the former pyrolysis systems, the pyrolysis process were carried out under the flow of inert gas medium and the residence time was varied by means of inert gas flow rate. Hence, some experiments of pyrolysis of coconut shell with the effect of different process parameters on the yield of liquid, gas and solid yield are described in this paper. The experiments were conducted with the aim of determining the optimum process conditions to maximize the liquid yield from the slow pyrolysis of coconut shell in a fixed bed reactor.

\section{Materials and Methods}

\subsection{Raw Material-Coconut Shell}

Samples of coconut shell in the present study were originated from Pollachi, Coimbatore district, located in the Tamilnadu, India. Immediately after getting, the coconut shells were sun dried for few days to remove the moisture content, after which they were ground in a high speed rotary cutting mill and screened by standard sieve (IS designation 460-1962) separator to give fractions of less than $0.15 \mathrm{~mm}, 0.15-0.30 \mathrm{~mm}, 0.30-0.60 \mathrm{~mm}, 0.60$ $1.18 \mathrm{~mm}$ and $1.18-1.80 \mathrm{~mm}$. The fixed carbon, volatiles and ash present in the sample were determined by ASTM standards. The elements carbon, hydrogen, nitrogen, oxygen and sulphur content on the sample were also identified by the ASTM standards. The calorific value and moisture content of the sample were measured with ASTM D 5865:2007 and ASTM D 3173:2003 standards respectively. The properties of sample, components and elements are given in Table 1.

Table 1. Components and elemental analysis of Coconut shell

\begin{tabular}{|c|c|}
\hline \multicolumn{2}{|l|}{ Components } \\
\hline Volatiles & $72.93 \%$ \\
\hline Fixed carbon & $19.48 \%$ \\
\hline Ash & $0.61 \%$ \\
\hline \multicolumn{2}{|l|}{ Elemental analysis ${ }^{\mathrm{a}}(\%)$} \\
\hline Carbon & $53.73 \%$ \\
\hline Hydrogen & $6.15 \%$ \\
\hline Oxygen ${ }^{b}$ & $38.45 \%$ \\
\hline Nitrogen & $0.86 \%$ \\
\hline Sulphur & $0.02 \%$ \\
\hline Calorific value (MJ/kg) & 20.88 \\
\hline Moisture content (\%) & $6.98 \%$ \\
\hline
\end{tabular}




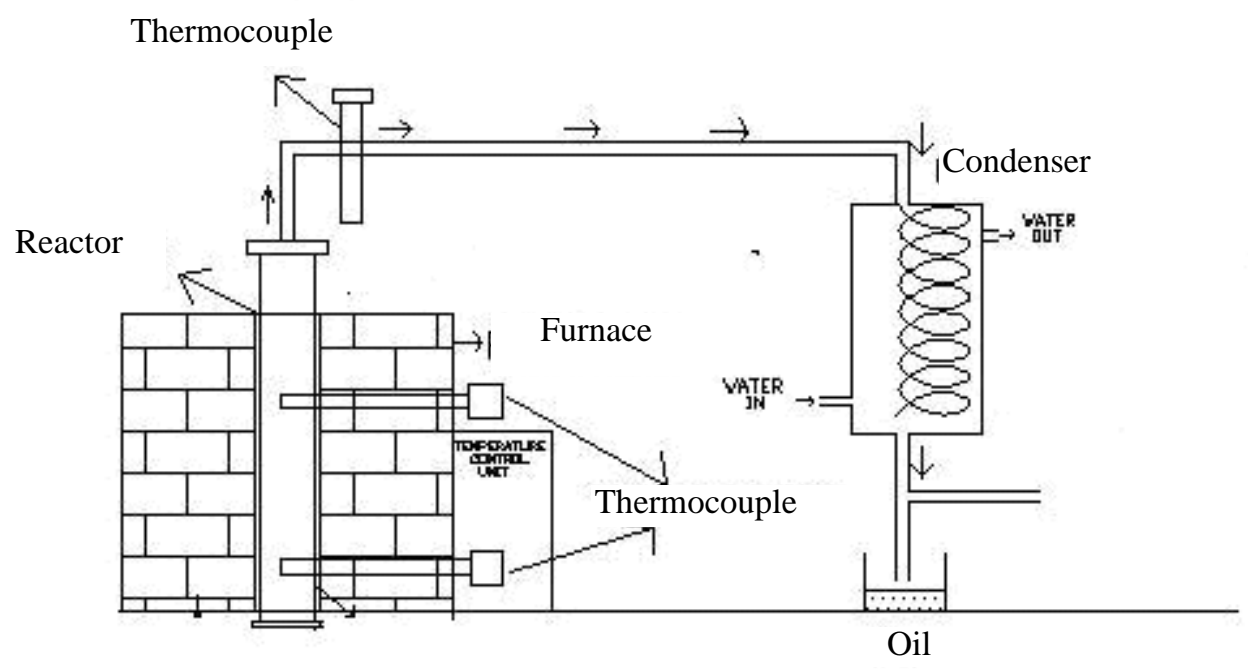

Figure 1. Pyrolyser Experimental Setup

\subsection{Experimental Apparatus and Procedure}

As shown in Fig. 1, the 316 stainless steel tubular reactors with a length of $200 \mathrm{~mm}$ and $300 \mathrm{~mm}$, and an internal and external diameter of $27 \mathrm{~mm}$ and $33 \mathrm{~mm}$ were used to conduct the experiments, respectively. In each run, a 15 $\mathrm{g}$ of the sample biomass was placed inside the reactor then the reactor was placed inside the electric furnace with the capacity of $2 \mathrm{kWh}$, which was specifically designed and manufactured for this study. The reactor was heated externally by an electric furnace. The temperature inside the reactor was measured by a $\mathrm{Cr}$ - $\mathrm{Al}$ : $\mathrm{K}$ type thermocouple. The temperature and heating rate was controlled by an external PID (Proportional-Integral-Derivative) controller. A $6.5 \mathrm{~mm}$ ID and $9 \mathrm{~mm}$ OD stainless steel pipe was used to connect the reactor and glass condenser. The connecting pipe between the reactor and the condenser system was maintained at $200^{\circ} \mathrm{C}$ to avoid condensation. The condensable liquid products (bio-oil + water) were collected in a $300 \mathrm{~mm}$ length coil type glass condenser. The temperature of the condenser was maintained at $25^{\circ} \mathrm{C}$ by circulating the water in the condenser. After each experiment, the condensed liquid was collected into the sample bottle and the liquid weight was calculated by the weight difference of sample bottle before and after the liquid was collected. After pyrolysis, the solid residue was removed and weighed. Then the gaseous phase was calculated from the material balance. The biomass sample input, liquid and solid char were measured by the electro balance weighing machine with an accuracy of $+/-0.01 \mathrm{~g}$. All the yields were at an average yield of at least three with an experimental measurement error of less than $\pm 1.5 \%$.

The experiments performed in the fixed-bed reactor were carried out in four groups. In the first, to determine the effect of the pyrolysis temperature on the coconut shell pyrolysis yields, a $15 \mathrm{~g}$ of the sample with the particle size of 1.18-1.80 $\mathrm{mm}$ was placed in the $200 \mathrm{~mm}$ length reactor then the reactor was placed inside the furnace and the temperature was raised at $60^{\circ} \mathrm{C} / \mathrm{min}$ to a final temperature of either $400,450,500,550$, or $600^{\circ} \mathrm{C}$ and held for until no further significant release of gas was observed. The sec- ond group of experiments was performed in order to determine the effect of particle size on the pyrolysis yields. The experiments were conducted at particle sizes less than $0.15 \mathrm{~mm}, 0.15-0.30 \mathrm{~mm}, 0.30-0.60 \mathrm{~mm}, 0.60-1.18 \mathrm{~mm}$ or $1.18-1.80 \mathrm{~mm}$. For all these experiments, the heating rate, the final pyrolysis temperature (based on the results of first group of experiments) and the reactor lengths were $60^{\circ} \mathrm{C} / \mathrm{min}, 550{ }^{\circ} \mathrm{C}$ and $200 \mathrm{~mm}$ respectively.

The third group of experiments was performed in a 200 $\mathrm{mm}$ length reactor to determine the effect of heating rate on the pyrolysis yield. At first, $15 \mathrm{~g}$ of sample was placed in the reactor then the reactor was placed inside the furnace and the temperature was raised at either $20^{\circ} \mathrm{C} / \mathrm{min}$, $40^{\circ} \mathrm{C} / \mathrm{min}$ or $60^{\circ} \mathrm{C} / \mathrm{min}$ by PID controller. For all these experiments, the final pyrolysis temperature and particle size were $550^{\circ} \mathrm{C}$ and $1.18-1.80 \mathrm{~mm}$ respectively, based on the results of the first and second group of experiments. Finally, the effect of residence time on the pyrolysis yield was determined by varying the reactor lengths. The experiments was performed with the reactor lengths of $200 \mathrm{~mm}$ and $300 \mathrm{~mm}$. Based on the first three groups of experiments the final pyrolysis temperature, particle size and heating rate were maintained at $550{ }^{\circ} \mathrm{C}, 1.18-1.80 \mathrm{~mm}$ and $60{ }^{\circ} \mathrm{C} / \mathrm{min}$ respectively.

The pyrolysis oil obtained at optimum condition was tested for its properties and functional groups. Fourier transform infrared spectroscopy (FT-IR) analysis was performed on a Perkin Elmer Spectrum device with a Resolution of $1.0 \mathrm{~cm}-1$ for finding the functional groups present in the bio oil.

\section{Results and Discussion}

\subsection{Effect of Temperature on the Pyrolysis Yield}

Figure 2 presents the product distribution from slow pyrolysis of coconut shell at a pyrolysis temperature of $400-600{ }^{\circ} \mathrm{C}$. The liquid and gas yield were increased from 38 to $43 \mathrm{wt} \%$ and 30 to $33 \mathrm{wt} \%$ respectively, when the pyrolysis temperature was increased from 400 to 
$600^{\circ} \mathrm{C}$, whereas the solid yield significantly decreased from 32 to 22 wt\%. The decrease of liquid yield and increase of gas yield were observed at higher temperature. The decrease in liquid and gas yield at lower temperature is due to incomplete decomposition of the shell (pyrolysis is not complete). Decrease in liquid and char yield and increase in gas yield at higher temperature is due to not only the secondary cracking of pyrolysis vapor but also solid char. Similar results were observed in the fixed - bed slow pyrolysis of rapeseed at $30^{\circ} \mathrm{C} / \mathrm{min}$ in which the liquid yield increased from 41 to $47 \mathrm{wt} \%$ when the pyrolysis temperature increased from $400^{\circ} \mathrm{C}$ to $550{ }^{\circ} \mathrm{C}$ (Ozlem and Kocker, 2004), but the liquid yield of safflower seed press cake and soybean cake were found to be 30 to $33 \mathrm{wt} \%$ and 26 to $30 \mathrm{wt} \%$ respectively at the same temperature range (Sensoz and Angin, 2008; Putin et al. 2002). This similarity and variation of the liquid yield could be due to the variation of the components present with individual biomass.

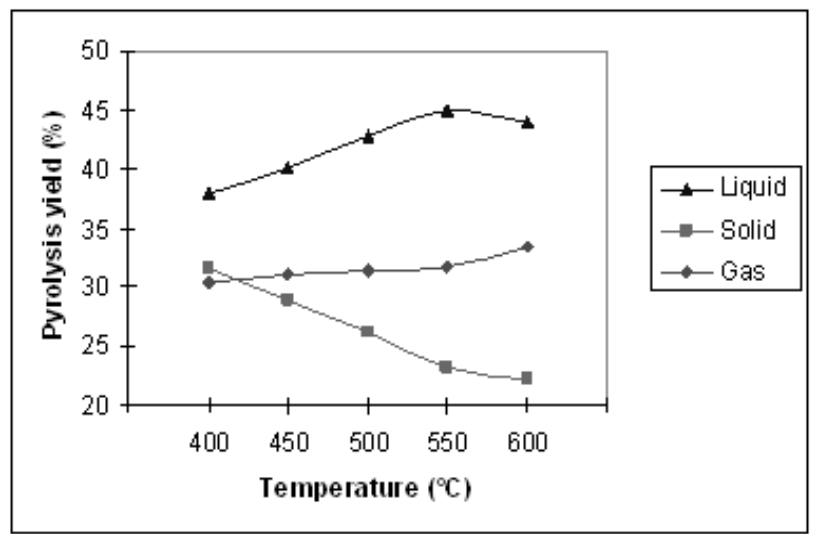

Figure 2. Yield of pyrolysis products at various pyrolysis temperatures

\subsection{Effect of Particle size on Pyrolysis Yield}

From Fig. 3, the solid and liquid yields are significantly increased as the particle size is increased from less than $0.15 \mathrm{~mm}$ to1.80 $\mathrm{mm}$ and gas yield is found to decrease. The study found that solid and liquid yield increases from 23 to $26 \mathrm{wt} \%$ and 37 to $43 \mathrm{wt} \%$ respectively and gas yield decreases from 39 to $30 \mathrm{wt} \%$ when the particle size is increased from less than 0.15 to $1.18-1.80 \mathrm{~mm}$. The increases in the solid yield with the increasing particle size for the sample biomass could be due to greater temperature gradient inside the particles. So that at a given time the core temperature is lower than that of the surface, which possibly gives rise to an increase in the solid yield (Zanzi et al. 2002). Decrease in particle size leads to decreases of liquid yield because the residence time of the volatiles in the reactor is longer, favor the cracking of hydrocarbons, when smaller particles are used (Sensoz et al. 2000). More residence time of volatiles inside the reactor leads to cracking of heavier molecules (tar) in to lower molecules at lower particle size ranges and it results in increase of gaseous product. There is a significant effect of particle size on the char, oil and gas yield in the pyrolysis of olive bagasse and pine sawdust (Sensoz et al. 2006; Wei et al. 2006).

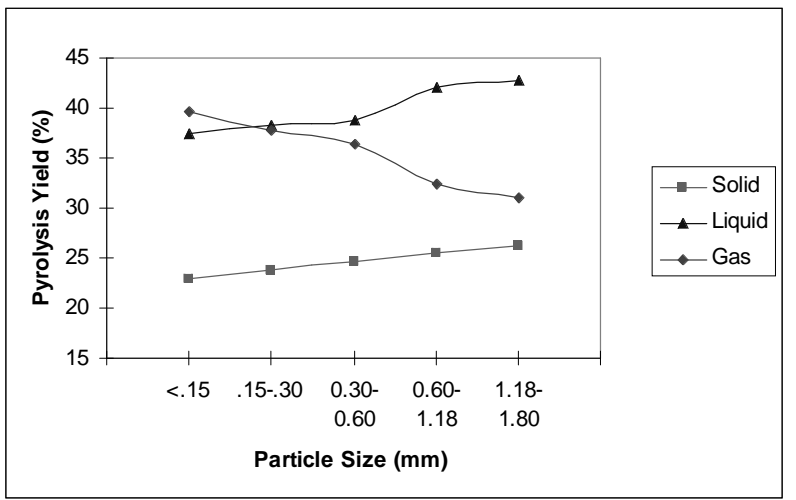

Figure 3. Yield of pyrolysis products with different particle size

\subsection{Effect of Heating Rate on Pyrolysis Yields}

Figure 4 shows the pyrolysis product yields of coconut shell at different heating rates of 20,40 and $60{ }^{\circ} \mathrm{C} / \mathrm{min}$ with a constant pyrolysis temperature of $550{ }^{\circ} \mathrm{C}$ and particle size of 1.18-1.80 $\mathrm{mm}$ in a $200 \mathrm{~mm}$ length reactor. The liquid yield was low at lower heating rate and increased with increase of heating rate; the liquid yield was $40 \mathrm{wt} \%$ at the heating rate of $20{ }^{\circ} \mathrm{C} / \mathrm{min}$ and increased to $43 \mathrm{wt} \%$ when the heating rate increased to $60^{\circ} \mathrm{C} / \mathrm{min}$. The gas yield also increased with increase of heating rate, but the char yield decreased with the increase of heating rate. The char yield was decreased from $29 \%$ to $25 \mathrm{wt} \%$ when the heating rate increased from $20^{\circ} \mathrm{C} / \mathrm{min}$ to $60{ }^{\circ} \mathrm{C} / \mathrm{min}$ (Fig. 4). The increase of the oil yield with the increase of heating rate may be due to higher heating rates that break the heat and mass transfer barriers in the particles (Haykiri et al. 2006). The cracking of the pyrolysis vapors at higher heating rates leads to increase of gas yield. The same trend was predicted by other researchers (Sensoz 2003; Sensoz and Angin, 2007; Onay 2007 and Karaosmanoglu et al. 1999) on pine bark, Safflower seed press cake, pistacia khinjuk seed and straw and stalk of the rapeseed plant.

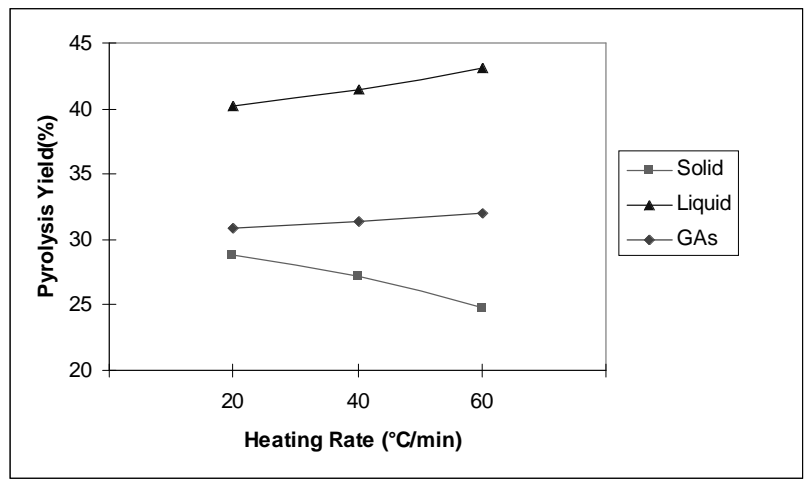

Figure 4. Effect of heating rate on pyrolysis yield

\subsection{Effect of Residence Time on Pyrolysis Yield}

The effect of residence time on the pyrolysis yield was investigated by varying the reactor length. Figure 5 shows the influence of residence time on the pyrolysis yield. The gas yield from $300 \mathrm{~mm}$ reactor was higher than that from the $200 \mathrm{~mm}$ length reactor. The liquid yield from $200 \mathrm{~mm}$ reactor was higher than that from the $300 \mathrm{~mm}$ reactor. This 

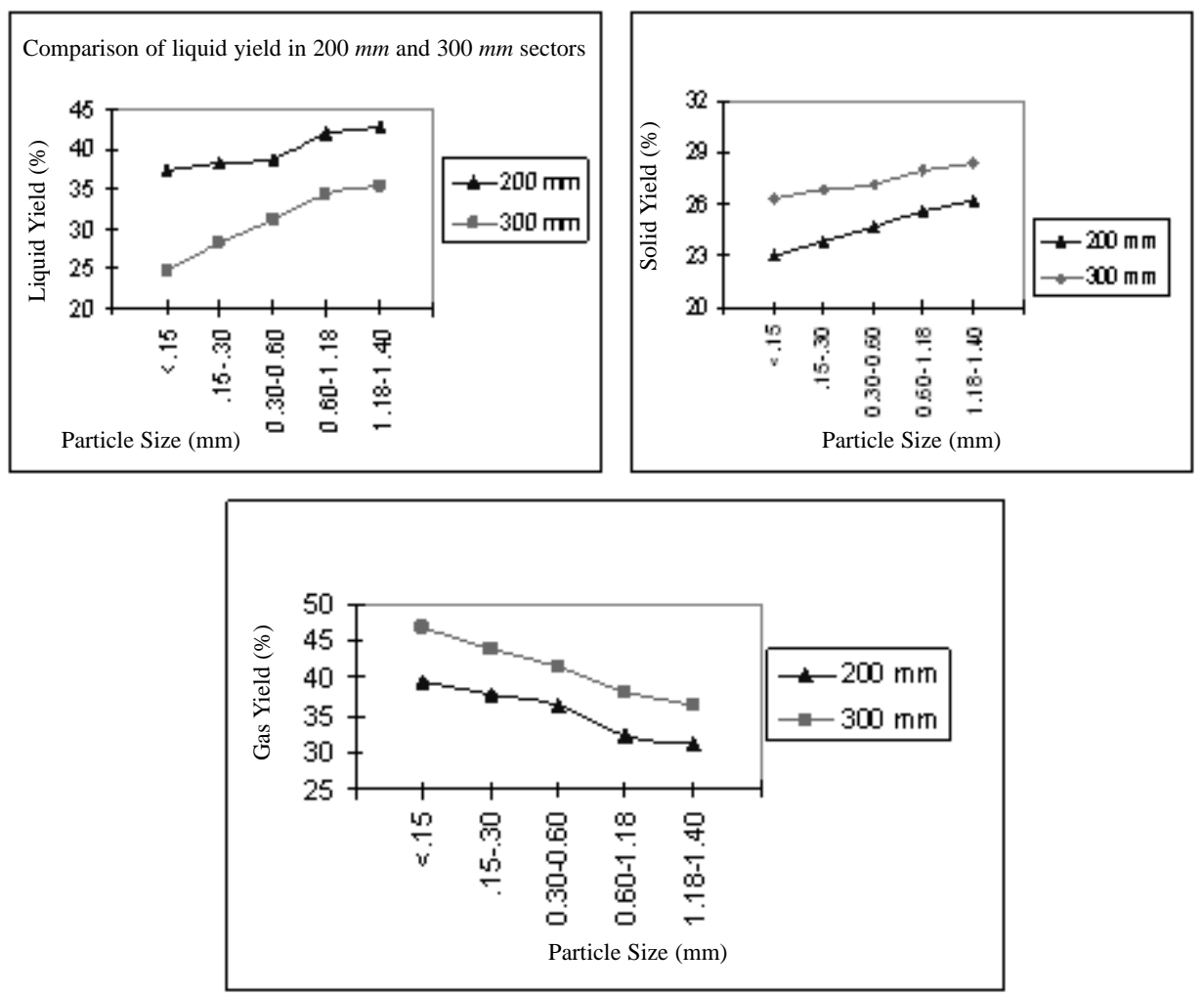

Figure 5. Effect of residence time on pyrolysis yield

shows the opposite trends in the liquid yield. This could be due to the secondary cracking of the liquid yield in the $300 \mathrm{~mm}$ length reactor due to prolonged residence time of the vapours inside the reactor. The solid residue yield in $300 \mathrm{~mm}$ reactor was higher than that in the $200 \mathrm{~mm}$ reactor.

\section{Properties of Pyrolysis Oil}

Physical properties were determined for the bio-oil using the American Standards for Testing and Materials (ASTM). The physical, chemical properties and calorific value of the bio-oil obtained under optimum conditions are given in Table 2 .

\section{Table 2. Properties of bio-oil under optimum conditions}

$\begin{array}{lc}\text { Properties } & \text { Bio-oil } \\ \text { Elemental (wt \%) } & \\ \text { Carbon } & 75.4 \\ \text { Hydrogen } & 11.7 \\ \text { Nitrogen } & 2.4 \\ \text { Oxygen } & 10.5 \\ \text { Density }\left(\mathrm{kg} / \mathrm{m}^{3}\right) & 1090 \\ \text { Viscosity, } 50^{\circ} \mathrm{C}(\mathrm{cSt}) & 36 \\ \text { Flash Point }\left({ }^{\circ} \mathrm{C}\right) & 80 \\ \text { Higher heating value }(\mathrm{MJ} / \mathrm{kg}) & 38.6\end{array}$

The IR spectrum of the bio-oil at optimum condition is given in Fig. 6. The $\mathrm{O}-\mathrm{H}$ stretching vibrations between 3200 and $3400 \mathrm{~cm}-1$ indicate the presence of phenols and alcohols. The $C-H$ stretching vibrations between 3200 and $3400 \mathrm{~cm}^{-1}$ and $C-H$ deformation vibrations between 1350 and $1475 \mathrm{~cm}^{-1}$ indicate the presence of alkanes. The $C=O$ stretching vibrations with absorbance between 1650 and $1750 \mathrm{~cm}^{-1}$ indicate the presence of ketones or aldehydes. The absorbance peaks between 1575 and $1675 \mathrm{~cm}^{-1}$ represent $C=C$ stretching vibrations indicative of alkenes and aromatics. The $\mathrm{C}-\mathrm{H}$ stretching and bending vibrations between 1380 and $1465 \mathrm{~cm}^{-1}$ indicates the presence of alkane groups in pyrolysis oils derived from biomass. Absorptions between 1300 and $900 \mathrm{~cm}^{-1}$ indicates the carbonyl components (ie. alcohols, esters, carboxylic acids or ethers). The absorbance peaks between 900 and $690 \mathrm{~cm}^{-1}$ represent $\mathrm{O}-\mathrm{H}$ stretching vibrations indicative of aromatic groups.

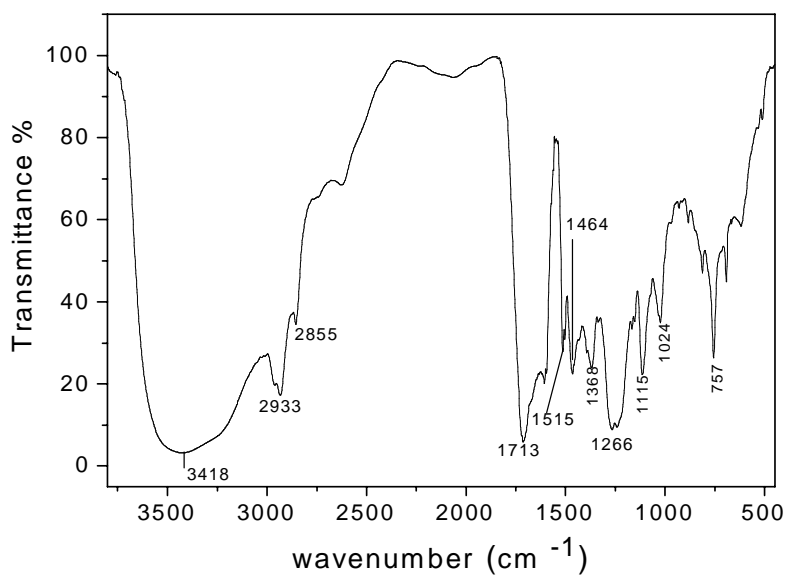

Figure 6. FT - IR spectra of pyrolysis oil 


\section{Conclusions}

In this study, pyrolysis experiments of the coconut shell are carried out in a fixed bed reactor with different pyrolysis temperature, particle size, heating rates and reactor length. The bio oil obtained at the optimum parameters are tested for finding its properties. The following are the findings from pyrolysis experiments of coconut shell in the fixed bed reactor:

- The optimum process conditions for maximizing the liquid yield of slow pyrolysis of coconut shell in a fixed bed are: pyrolysis temperature $550{ }^{\circ} \mathrm{C}$, particle size $1.18-1.80 \mathrm{~mm}$, heating rate $60{ }^{\circ} \mathrm{C} / \mathrm{min}$ and the reactor length $200 \mathrm{~mm}$. The maximum liquid yield of $45 \mathrm{wt} \%$ was obtained at the optimum condition.

- Employing higher particle size results in more amounts of liquid and solid yield and less amount of gas yield compared to lower particle size. The gas yield decreases from 40 to $30 \mathrm{wt} \%$ when particle size is increased from less than 0.15 to $1.8 \mathrm{~mm}$.

- The liquid yield increased from 40 to $43 \mathrm{wt} \%$ when the heating rate was increased from $20{ }^{\circ} \mathrm{C} / \mathrm{min}$ to $60^{\circ} \mathrm{C} / \mathrm{min}$. The effect of heating rate on the pyrolysis yield is not significant compared to other parameters in this study.

- The rapid devolatilization of cellulose and hemi cellulose increased the pyrolysis conversion from 69 to 88 wt $\%$ when the temperature was increased from 400 to $550^{\circ} \mathrm{C}$.

- The maximum liquid yield of $43 \mathrm{wt} \%$ and $35 \mathrm{wt} \%$ were obtained at reactor length of $200 \mathrm{~mm}$ and $300 \mathrm{~mm}$ respectively.

- The elemental composition of bio-oil is found to be better than that of feedstock. The heating value of the bio-oil is found to be similar to that of diesel fuel. FTIR analysis showed that the bio-oil composition was dominated by oxygenated species. The high oxygen content is reflected by the presence of mostly oxygenated fractions such as carboxyl and carbonyl groups produced by pyrolysis of the cellulose and phenolic and methoxy groups produced by pyrolysis of the lignin.

\section{References}

Abdullah, A. and Gerhauser, H., 2008, "Bio-Oil Derived from Empty Fruit Bunches Fuel," Vol. 87, pp. 26062613.

Afrane, G. and Osei-Wusu Achaw., 2008, "Effect of the Concentration of Inherent Mineral Elements on the Adsorption Capacity of Coconut Shell-Based Activated Carbon," Bioresource Technology; Vol. 99, pp. 6678-6682.

Alberto, J., Tsamba., Weihong Yang. and Wlodzimierz
Blasia., 2006, "Pyrolysis Characteristics and Global Kinetics of Coconut and Cashew Nut Shells," Fuel Processing Technology, Vol. 87, pp. 523-550.

Amuda, O.s., Giwa, A.A. and Bello, I.A., 2007, "Removal of Heavy Metal from Industrial Wastewater using Modified Activated Coconut Shell Carbon," Biochemical Engineering Journal, Vol. 36, pp. 174181.

Das, P., Sreelatha, T. and Anuradda, G., 2004, "Bio Oil from Pyrolysis of Cashew Nut Shell-Characterization and Related Properties," Biomass and Bioenergy, Vol. 27, pp. 265-275.

Dinesh Mohan., Kunwar, P. Singh and Vinod, K. Singh., 2008, "Wastewater Treatment using Low Cost Activated Carbons Derived from Agricultural by Products - A Case Study," Journal of Hazardous materials, Vol. 152, pp. 1045-1053.

Gratuito, M.K.B., Panyathanmaporn, T. and Chumnanklang, R.A., 2008, "Production of Activated Carbon from Coconut Shell: Optimization using Response Surface Methodology," Bioresource Technology; Vol. 99, pp. 4887-4894.

Haykiri-Acman, H., Yaman, S. and Kucukbayrak, S., 2006, "Effect of Heating Rate on the Pyrolysis Yields of Rapeseed," Renewable Energy, Vol. 31, pp. 803810.

Karaosmanoglu, F., Tetik, E. and Gollu, E., 1999, "Bio Fuel Production using Slow Pyrolysis of the Straw and Stalk of the Rapeseed Plant," Fuel Processing Technology, Vol. 59, pp. 1-12.

Onay, O., 2007, "Fast and Catalytic Pyrolysis of Pistacia Khinjuk Seed in a Well-Swept Fixed Bed Reactor," Fuel, Vol. 86, pp. 1452-1460.

Onay, O., 2007, "Influence of Pyrolysis Temperature and Heating Tate on the Production of Bio-Oil and Char from Safflower Seed by Pyrolysis, using a WellSwept Fixed-Bed Reactor," Fuel Processing Technology, Vol. 88, pp. 523-531.

Onay, O. and Kochar, O.M., 2006, "Pyrolysis of Rapeseed in a Free Fall Reactor for Production of Bio Oil," Fuel, Vol. 85, pp. 1921-1928.

Ozlem, O. and Kockar, O.M., 2004, "Fixed-Bed Pyrolysis of Rapeseed," Biomass and Bioenergy , Vol. 26, pp. 289-299.

Putun, A.E., Apaydin, E. and Putun, E., 2002, "Bio-Oil Production from Pyrolysis and Steam Pyrolysis of Soybean-Cake," Product Yields and Composition, Energy, Vol. 27, pp. 703-713.

Sensoz, .S. and Angin, D., 2008, "Pyrolysis of Safflower Seed Press Cake: Part 1. The Effects of Pyrolysis Parameters on the Product yields," Bio Resource Technology, Vol. 99(13), pp. 5492-5497.

Sensoz, S., 2003, "Slow Pyrolysis of Wood Barks from Pinus Brutia Ten.and Product Compositions," Bio Resource Technology, Vol. 89, pp. 307-311.

Sensoz, S., Angin, D. and Yorgun, S., 2000, "Influence of Particle Size on the Pyrolysis of Rapeseed (Brassica Napus L.): Fuel Properties of Bio-Oil," Biomass and Bioenergy, Vol. 19, pp 271-279. 
Sensoz, S., Demiral, I. and Gercel, H.F., 2006, "Olive Bagase Pyrolysis," Bio Resource Technology, Vol. 97, pp. 429-436.

Sensoz,S. and Angin, D., 2007, "Pyrolysis of Safflower Seed Press Cake: Part 1. The Effects of Pyrolysis Parameters on the Product Yields," Bioresource Technology, Vol. 99(13), pp. 5492-5497.

Suat Ucar., Ahmet., R. and Ozkan., 2008, "Characterization of Products from the Pyrolysis of Rapeseed Oil Cakk," Bioresource Technology, Vol. 99, pp. 8771-8776.

Varol, E.A., Putun, E. and Putun, A.E., (2007), Slow Pyrolysis of Pistachio Shell," Fuel, Vol. 86, pp. 18921899.

Wei, L., Shaoping, L., Zhang, L. and Zhang, H., 2006, "Characteristic of Fast Pyrolysis of Biomass in a Free Fall Reactor," Fuel Processing Technology, Vol. 87, pp. 863-871.
Wel Su, Li Z. and Yapping, Z., 2006, "Preparation of Micro Porous Activated Carbon from Raw Coconut Shell by Two-Step Procedure," Chinese Journal of Chemical Engineering, Vol. 14, pp. 266-269.

Yun Ju Hwang, Jeong, S.K. and Shin, J.S., 2008, "High Capacity Disordered Carbons obtained from Coconut Shells as Anode Materials for Lithium Batteries," Journal of Alloys and Compounds, Vol. 448, pp. 141147.

Zabaniotou, A., Ioannidou, O., 2007, "Evaluation of Utilization of Corn Stalks for Energy and Carbon Material Production by using Rapid Pyrolysis at High Temperature," Fuel, Vol. 87(6), pp. 834-843.

Zanzi, R., Sjostrom, K. and Bjornbom, E., 2002, "Rapid Pyrolysis of Agricultural Residues at High Temperature," Biomass and Bio Energy, Vol. 23, pp. 357-366. 